\title{
The Epidemiology of Non-Melanocytic Benign and Malignant Skin Tumors in Pediatric Patients Attending to the Dermatology Department
}

\author{
Gulsen Tukenmez Demircia, e, Guldehan Atis ${ }^{\mathrm{b}}$, Ilknur Kivanc Altunay ${ }^{\mathrm{c}}$, \\ Damlanur Sakiz
}

\begin{abstract}
Background: Non-melanocytic skin tumors are rarely seen in pediatric patients; although they are mostly benign, they remain to be elucidated by histopathological examination. The objective of the study was to describe the epidemiology of non-melanocytic skin tumors in children attending to our dermatology department.
\end{abstract}

Method: The histopathologic studies of all skin punch and excisional biopsies of children up to 16 years old referred to our dermatology department between January 2007 and January 2012 were reviewed retrospectively. Melanocytic tumors and cystic and infectious lesions were excluded. Age, sex, location, and histopathologic diagnosis were recorded. The skin tumors were categorized.

Results: A total of 4,126 skin tumors were analyzed histopathologically, and 203 of the lesions were from children up to 16 years of age. Ninety-seven of the lesions from 91 patients were non-melanocytic skin tumors. Forty-seven (51.64\%) were male, 44 (48.36\%) were female, and mean age was $10.55 \pm 4.31$ years. Malignant tumor was $1.03 \%$ (one tumor) and benign tumors were $98.97 \%$ (96 tumors) of all. The most frequent non-melanocytic skin tumor was pilomatricoma with 22 lesions (22.68\%), followed by pyogenic granuloma with 18 lesions (18.54\%), and nevus sebaceous with 10 (10.3\%) lesions. Cutaneous leukemic infiltrate was found to be the only malignant skin tumor in the study group. The most frequently affected age group was children aged $>13$ to $\leq 16$ years, which included 38 patients $(41.7 \%)$. The majority of lesions were on head and scalp (32 tumors, 32.96\%), followed by trunk (28 tumors, 28.84\%) and upper limbs (22 tumors,

Manuscript accepted for publication April 21, 2015

aDermatology Department, Baskent University Istanbul Hospital, Istanbul, Turkey

bDermatology Department, Siyami Ersek Cardiovasculer Surgery Hospital, Istanbul, Turkey

'Dermatology Department, Sisli Etfal Training and Research Hospital, Istanbul, Turkey

dPathology Department, Bakirkoy Sadi Konuk Training and Research Hospital, Istanbul, Turkey

${ }^{e}$ Corresponding Author: Gulsen Tukenmez Demirci, Baskent University Istanbul Hospital, Mahir Iz cad. No. 43, Altunizade, Istanbul, Turkey.

Email: gulsentukenmez@yahoo.com

doi: http://dx.doi.org/10.14740/jocmr2190w
$22.75 \%)$

Conclusion: The ratio of malignant to benign skin tumors in pediatric patients is found to be small. Pilomatricoma, pyogenic granuloma and nevus sebaceous are found to be the most frequent non-melanocytic skin tumors of children. The ratio of malignant tumors is very rare.

Keywords: Pyogenic granuloma; Nevus sebaceous; Pilomatricoma

\section{Introduction}

The skin of children has different histologic, physiologic, and immunologic characteristics than the skin of adults. Pediatric dermatology is therefore an emerging and growing specialty within the fields of pediatrics and general dermatology [1]. Malignant tumors, such as basal cell carcinoma, squamous cell carcinoma, and melanoma, which are the most common malignant skin tumors in adulthood, are very rare in childhood [2]. Only $1-2 \%$ of the skin tumors excised from children are malignant [3]. Although most of the skin tumors seen in children are benign, histopathological confirmation is needed for an exact diagnosis if the lesions are non-melanocytic and there are no other diagnostic approaches. In this study, we aimed to perform an epidemiologic survey of non-melanocytic skin tumors that were biopsied or excised from patients aged 16 years or younger at the Dermatology Department of Sisli Etfal Training and Research Hospital, in Istanbul, over a period of 5 years.

\section{Materials and Methods}

The study was performed in the Dermatology and Pathology Departments at Sisli Etfal Training and Research Hospital in Istanbul. From the database of the Pathology Department, we extracted all histopathology reports of patients aged 16 years old and younger with skin tumors who had been referred to dermatology department from January 2007 to January 2012 (a 5 -year period). Melanocytic tumors and cystic and infectious lesions were excluded. The age, sex, location of the tumor, and histopathologic diagnoses of the patients were recorded. The non-melanocytic skin tumors were categorized as skin adnexal 


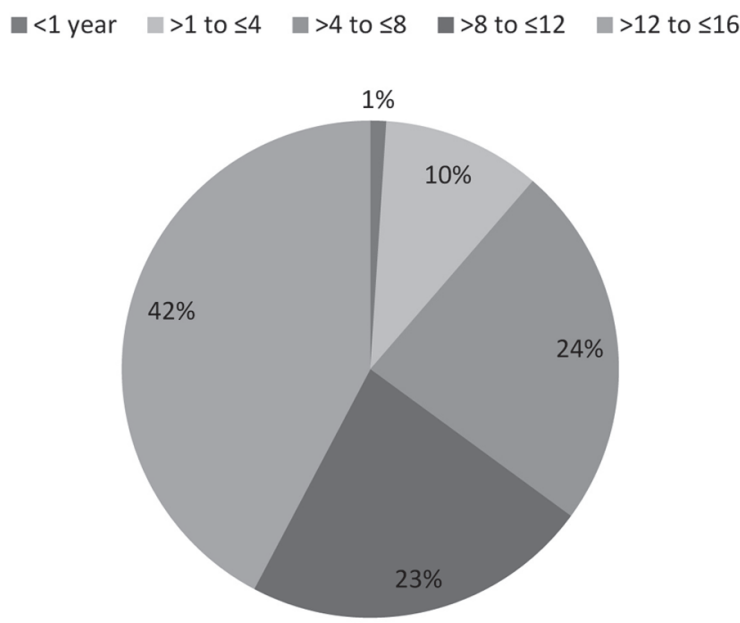

Figure 1. Distribution of non-melanocytic skin tumors according to age group.

tumors; vascular tumors; tumors and tumor-like proliferations of fibrous and related tissues; non-lymphoid cutaneous infiltrates; tumors of muscle, cartilage, and bone; tumors of the epidermis; neural and neuroendocrine tumors; tumors of fat; and cutaneous metastases. The most common skin tumors were also grouped according to the age and sex of the patient and the location of the tumor.

\section{Results}

We found that 203 (4.92\%) of the 4,126 skin tumors were from children up to 16 years of age, and 97 (47.78\%) skin tumors, from 91 patients, were non-melanocytic, while $106(52.22 \%)$ of the lesions were diagnosed as melanocytic, cystic, or infectious. Among the patients, 47 (51.64\%) were male, while 44 $(48.36 \%)$ were female. The mean age was $10.37 \pm 4.37$ years.
Thirty-eight skin tumors $(41.7 \%)$ were found in patients aged $>13$ to $\leq 16$ years, $21(23.1 \%)$ skin tumors were found in patients aged $>8$ to $\leq 12$ years, $22(24.2 \%)$ were found in patients aged $>4$ to $\leq 8$ years, nine $(9.9 \%)$ were found in patients aged $>1$ to $\leq 4$ years, and one $(1.1 \%)$ was found in a patient under 1 year of age (Fig. 1).

The most common biopsy site was the head and scalp (n $=32,32.96 \%)$, followed by the trunk $(\mathrm{n}=28,28.84 \%)$, the upper $\operatorname{limbs}(\mathrm{n}=22,22.75 \%)$, the lower limbs $(\mathrm{n}=8,8.24 \%)$, the genitals $(\mathrm{n}=3,3.9 \%)$, or the site that was not mentioned ( $\mathrm{n}$ $=4,4.12 \%$ ) (Fig. 2).

The five most common histopathologic diagnoses were pilomatricoma (22 tumors, 22.68\%), pyogenic granuloma (18 tumors, 18.54\%), nevus sebaceous (10 tumors, 10.3\%), fibroepithelial polyp (six tumors, 6.18\%), and juvenile xanthogranuloma (five tumors, 5.15\%). The most commonly diagnosed histopathological group was adnexal tumors. The most common diagnoses in this group were pilomatricoma and nevus sebaceous. The second most commonly diagnosed group was vascular tumors. Pyogenic granuloma and capillary hemangioma were the most frequent diagnosis in this group. A cutaneous leukemic infiltrate was the only malignant skin tumor in the study group (1.03\%). The most common diagnoses by age group are shown in Table 1 .

There were five boys and 13 girls with pilomatricoma, and their mean age was $10.88 \pm 3.42$ years. The pilomatricomas were located on the upper limbs (13), the trunk (three), the head and scalp (five), or the location that was not mentioned (one). Among these patients, $16(88.89 \%)$ had single lesions, while two patients $(11.11 \%$ ) had multiple lesions (Table 2).

The mean age of the children (12 males and six females) with pyogenic granuloma was $11.66 \pm 3.83$ years. The pyogenic granulomas were located on the head and scalp (eight), the trunk (seven), the upper limbs (two), and the genitals (one) (Table 2).

There were seven males and three females with nevus sebaceous. Their mean age was $14.11 \pm 2.10$ years. All the nevus sebaceous lesions were located on the head and scalp (Table 2).

\section{Localization}

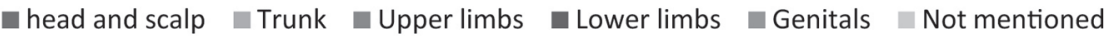



Figure 2. The location of non-melanocytic skin tumors. 


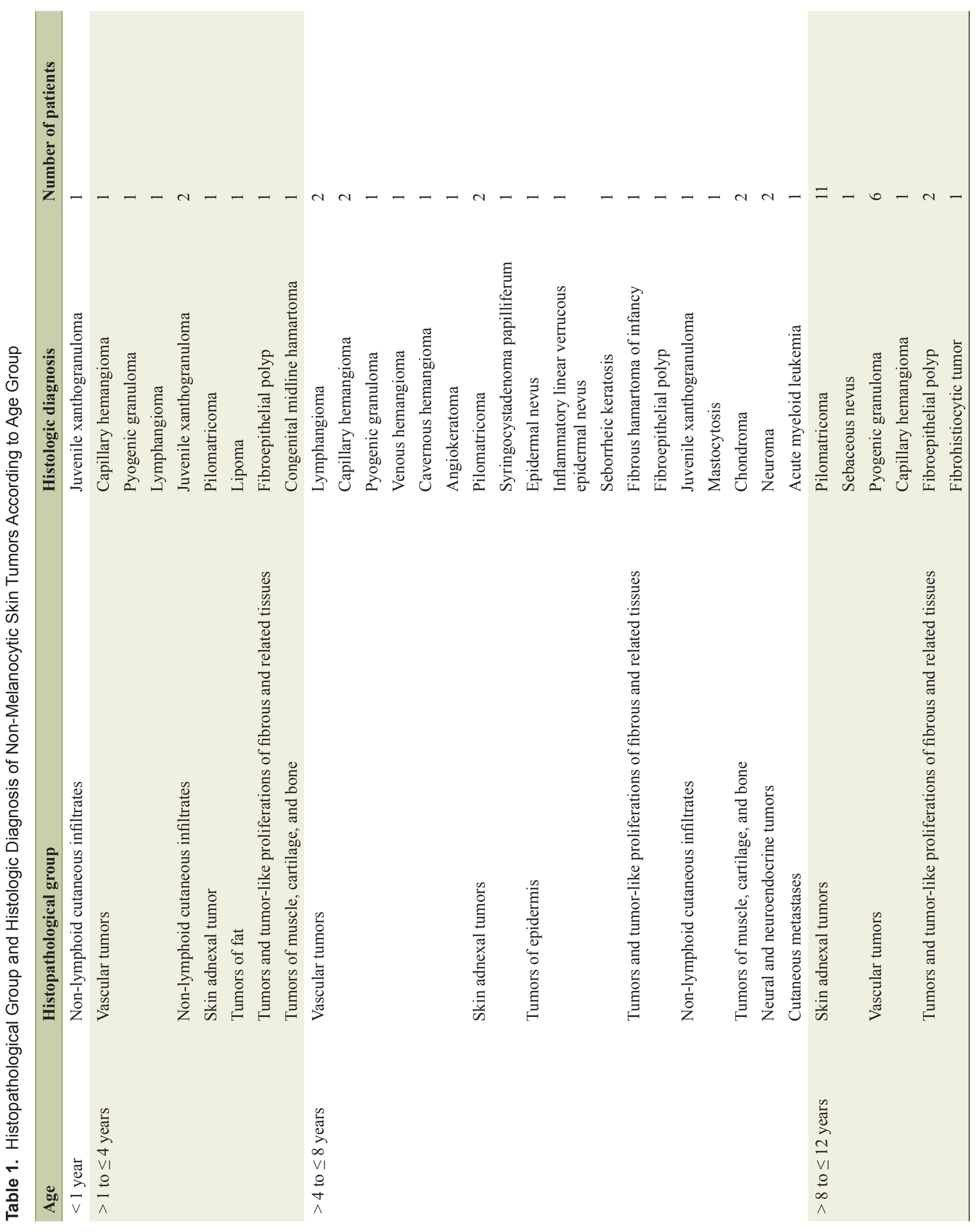




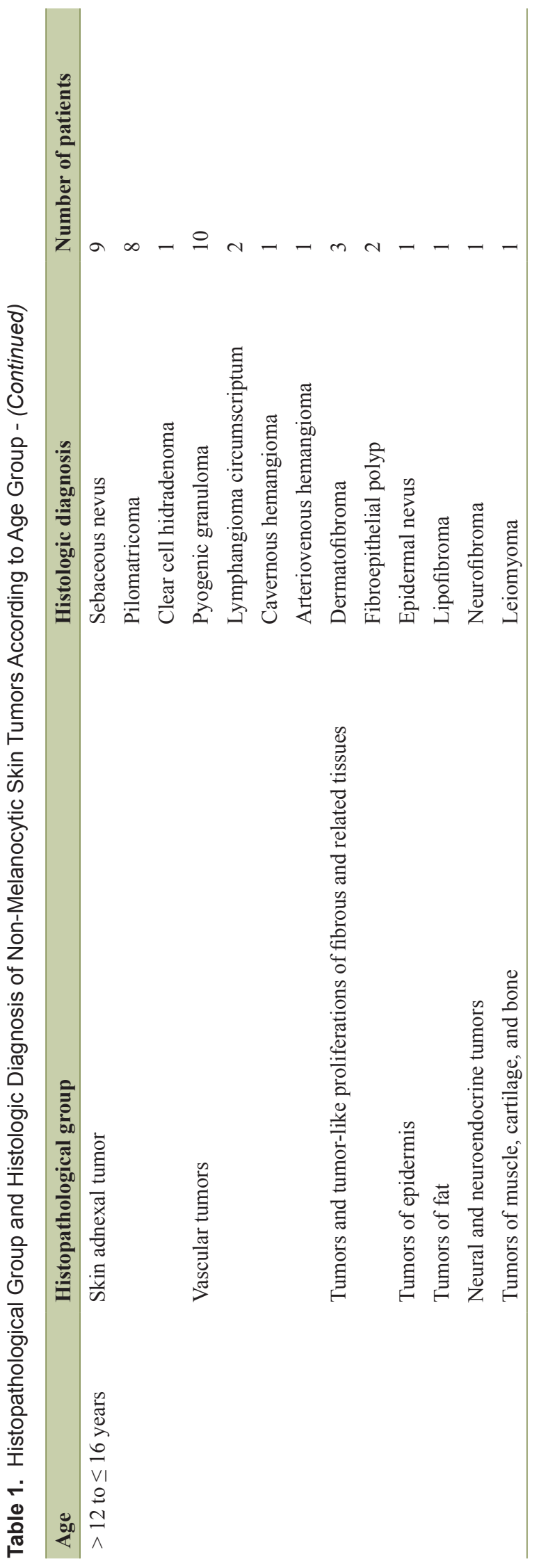

\section{Discussion}

We found that 203 of the 4,126 histopathologically diagnosed skin tumors occurred in pediatric patients up to 16 years old, and these cases were used in our study. Thus, the percentage of the total skin tumors from the pediatric patients $(4.92 \%)$ was found to be small in comparison with the adult population presenting to our dermatology department. We excluded melanocytic, cystic, and infectious lesions in order to define the authentic frequency and epidemiology of the more uncommon non-melanocytic skin tumors in children. In the study by Lopez et al [1], melanocytic tumors were the most frequent diagnosis, followed by pilomatricoma. We also found that pilomatricoma was the most common skin tumor (after excluding melanocytic lesions), which matched the study by Lopez et al.

Pilomatricoma is the most common benign skin tumor in pediatric patients, and it occurs mainly in the head and neck region $[4,5]$. Lucas et al reported on non-melanocytic benign skin tumors in their study and found that pilomatricoma was the most frequent benign skin tumor [6]. Guinot-Moya et al found that pilomatricoma tends to present in children and that it has a slight male predilection. Only $2.42 \%$ of cases presented multiple lesions, nearly all the cases presented as single lesions, and the most common localizations were the head and orofacial zones [7]. In a retrospective study, out of a total of seven patients, five $(71 \%)$ were female and two $(29 \%)$ were male [8]. In our study, we found that 16 patients $(88.89 \%)$ had single lesions and two patients $(11.11 \%)$ had multiple lesions. Among these patients, 13 (72.22\%) were female, whereas five $(27.78 \%)$ were male. The most common localization was the upper limbs, followed by the head and scalp and the trunk.

Pyogenic granuloma is another common skin tumor in children. These vascular-papular, rapidly growing erythematous lesions develop most commonly on the head, neck, extremities, and fingers [9]. We found that pyogenic granuloma was the second most frequent non-melanocytic skin tumor in our study. In a retrospective study conducted by Pagliai et al, 128 children had a clinical diagnosis of pyogenic granuloma, and the locations of the lesions were reported for 108 patients, with the most common locations for pyogenic granulomas being the head and neck (76.9\%), followed by the chest and back $(11.9 \%)$, the upper extremities, and the lower extremities $(2.8 \%)$ [10]. In our study, the most common location for pyogenic granulomas was the head and scalp (eight patients, $44.44 \%$ ), followed by the trunk (seven patients, $38.88 \%$ ), the upper limbs (two patients, $11.11 \%$ ), and the genitals (one patient, $5.5 \%$ ). Our results are similar to their study.

Nevus sebaceous was the third most common non-melanocytic skin tumor in our study. Ten patients had nevus sebaceous tumors, and all of these were located on the head and scalp. Nevus sebaceous is a kind of classical nevus or congenital hamartomatous disorder. The prevalence of nevus sebaceous is $0.3 \%$ [11]. More than $90 \%$ of sebaceous nevi involve the head, mainly on the scalp, and such lesions present at birth. In $10-30 \%$ of cases, secondary skin neoplasms develop on the nevus, usually in adulthood $[12,13]$. No other skin neoplasms were found on the nevus sebaceous in our patients, as our study population comprised young patients under the age of 16 . 
Table 2. The Mean Age and Gender of the Patients and the Location of the Pilomatricoma, Pyogenic Granuloma, and Nevus Sebaceous Tumors

\begin{tabular}{llll}
\hline & Pilomatricoma & Pyogenic granuloma & Nevus sebaceous \\
\hline $\begin{array}{l}\text { Mean age } \\
\text { Gender }\end{array}$ & $10.88 \pm 3.42$ & $11.66 \pm 3.83$ & $14.11 \pm 2.10$ \\
$\quad$ Female & $13(72.22 \%)$ & $6(33.33 \%)$ & $3(30 \%)$ \\
$\quad \begin{array}{l}\text { Male } \\
\text { Location }\end{array}$ & $5(27.78 \%)$ & $12(66.66 \%)$ & $7(70 \%)$ \\
$\quad$ Head and scalp & $5(22.72 \%)$ & $8(44.44 \%)$ & $10(100 \%)$ \\
Trunk & $3(13.62 \%)$ & $7(38.88 \%)$ & - \\
Upper limbs & $13(59.12 \%)$ & $2(11.11 \%)$ & - \\
Lower limbs & - & - & - \\
Genitals & - & $1(5.5 \%)$ & - \\
Not mentioned & $1(4.54 \%)$ & - & - \\
\hline
\end{tabular}

We found only one patient (1.03\%) with a malignant nonmelanocytic skin tumor in our study. In their study, Hamm et al reported that only $1-2 \%$ of all skin tumors excised from infants and children were malignant [12]. The single patient with a malignant skin tumor was a 5-year-old boy with leukemia cutis who was diagnosed with acute non-lymphocytic leukemia (ANLL). In a retrospective study, Tsukimoto showed that cutaneous leukemia developed in $15.9 \%$ of all patients with ANLL, and Tsukimoto suggested that cutaneous leukemia tends to occur early in infants with ANLL [14].

\section{Conclusion}

In conclusion, the ratio of malignant to benign skin tumors in pediatric patients is found to be low. Children aged $>13$ to $\leq$ 16 years had the highest ratio. The majority of lesions were on the head and scalp. Pilomatricoma, pyogenic granuloma, and nevus sebaceous were found to be the most frequent nonmelanocytic benign skin tumors. Although malignant tumors are very rare, histopathological examination is still necessary for confirmation.

\section{References}

1. Lopez V, Martin JM, Monteagudo C, Jorda E. [Epidemiology of pediatric dermatologic surgery: a retrospective study of 996 children]. Actas Dermosifiliogr. 2010;101(9):771-777.

2. Rogers HW, Weinstock MA, Harris AR, Hinckley MR, Feldman SR, Fleischer AB, Coldiron BM. Incidence estimate of nonmelanoma skin cancer in the United States, 2006. Arch Dermatol. 2010;146(3):283-287.

3. Pearce MS, Parker L, Cotterill SJ, Gordon PM, Craft AW.
Skin cancer in children and young adults: 28 years' experience from the Northern Region Young Person's Malignant Disease Registry, UK. Melanoma Res. 2003;13(4):421426.

4. Pulvermacker B, Seroussi D, Haddad R, Mitrofanoff M. [Pilomatricoma or calcifying epithelioma of Malherbe. A pediatric review of 89 cases]. Ann Chir Plast Esthet. 2007;52(1):39-42.

5. Pirouzmanesh A, Reinisch JF, Gonzalez-Gomez I, Smith EM, Meara JG. Pilomatrixoma: a review of 346 cases. Plast Reconstr Surg. 2003;112(7):1784-1789.

6. Lucas A, Betlloch I, Planelles M, Martinez T, Perez-Crespo M, Mataix J, Belinchon I. Non-melanocytic benign skin tumors in children. Am J Clin Dermatol. 2007;8(6):365-369.

7. Guinot-Moya R, Valmaseda-Castellon E, Berini-Aytes L, Gay-Escoda C. Pilomatrixoma. Review of 205 cases. Med Oral Patol Oral Cir Bucal. 2011;16(4):e552-555.

8. Yencha MW. Head and neck pilomatricoma in the pediatric age group: a retrospective study and literature review. Int J Pediatr Otorhinolaryngol. 2001;57(2):123-128.

9. Patrice SJ, Wiss K, Mulliken JB. Pyogenic granuloma (lobular capillary hemangioma): a clinicopathologic study of 178 cases. Pediatr Dermatol. 1991;8(4):267-276.

10. Pagliai KA, Cohen BA. Pyogenic granuloma in children. Pediatr Dermatol. 2004;21(1):10-13.

11. Price HN, Zaenglein AL. Diagnosis and management of benign lumps and bumps in childhood. Curr Opin Pediatr. 2007;19(4):420-424.

12. Hamm H, Hoger PH. Skin tumors in childhood. Dtsch Arztebl Int. 2011;108(20):347-353.

13. Kim JH, Park HY, Ahn SK. Nevus sebaceous accompanying secondary neoplasms and unique histopathologic findings. Ann Dermatol. 2011;23(Suppl 2):S231-234.

14. Tsukimoto I. Extramedullary relapse in childhood leukemia. Acta Paediatr Jpn. 1991;33(4):540-547. 